\title{
Aristotle on Joint Perception and Perceiving that We Perceive
}

\author{
Rosemary Twomey
}

While most interpreters take the opening of De Anima III 2 ("Since we perceive that we see and hear [...]") to be an oblique reference to some sort of conscious awareness, I argue that Aristotle intends to explain what I call 'joint perception': when conjoined with Aristotle's subsequent claim that perceiving and being perceived are the same activity, the metaperception underpins the perception of a unified object. My interpretation is shown to have a more satisfactory account of the aporiai that follow. While I argue that the immediate focus of the metaperceptual account is joint perception, it may also be applicable to other kinds of complex (i.e. non-special) perception, which I briefly consider in the closing section.

Aristotle opens De Anima [DA] III 2 by claiming that we perceive that we see and hear. Traditional interpretations read an allusion to conscious awareness here, and they understand Aristotle's subsequent remarks as developments of his theory of consciousness. ${ }^{1}$ In this paper I will suggest an alternative interpretation, according to which he has a different though equally ubiquitous perceptual phenomenon in mind: the unified perception of an object's properties across sensory modalities, which I call 'joint perception.' Aristotle should feel an obligation to provide an account of joint perception, for Plato has argued in Theaetetus that the domain of perception is significantly restricted. Specifically, Plato claims that the senses can only perceive the objects proper to them: qualities that prima facie seem perceptible by more than one sense-his examples include being (ousia), sameness and difference, number, beauty and ugliness, and goodness and badness — are actually examined by the soul itself rather than perceived through the senses. ${ }^{2}$ Accordingly, Plato has Socrates

\footnotetext{
${ }^{1}$ Accounts diverge on what kind of conscious awareness is under consideration; I will return to this below; fn. 28.

${ }^{2}$ Plato uses several terms here for what the soul does in grasping these qualities, including dianoein [185a4, 185a9, 185b7], episkopein [185b5, 185c1, 185e2, 185e7], lambanein [185b8], skopein
} 
argue that our grasp of these common properties cannot be accomplished by any of the individual special senses. Rather, there must be some underlying psychological unity that brings the senses together with judgment. Plato thus rejects not only joint perception, but all complex perception, i.e. all activities of perception that go beyond the mere reception, by one of the five senses, of that sense's paradigmatic-hereafter 'special'-sense object. The appearance of unified perception actually arises from an examination of the sense contents of the special senses conducted by the soul itself, not by or through the sense organs.

But this conclusion is unacceptable to Aristotle. According to his theory of perception, there are many objects that are perceptible by multiple senses. He calls these the common objects (ta koina), and he takes them to include such features as magnitude, figure, motion, number, and, in some places at least, time. ${ }^{3}$ Similarly, Aristotle claims that the perceptual capacity is able to integrate information across the senses ${ }^{4}$, though he is not insensitive to the complications this introduces. ${ }^{5}$ Indeed, Aristotle's biological taxonomy holds that non-human animals are limited to the perceptual and nutritive capacities, so doing justice to animal psychology will require ascribing complex activities to the perceptual capacity. ${ }^{6}$ But while Aristotle's perceptual capacity must be more wide-ranging than Plato's, it is not immediately clear how Aristotle justifies its expansion. Throughout the second half of De Anima Book II, Aristotle provides an account of each special sense in terms of its proper object, medium, and sense organ. In his presentation, the differences among the individual senses are stressed rather than minimized, yet joint perception (and other phenomena, including perception of the common objects and perceptual discrimination) requires a synthesis. Moreover, as we will see, the general metaphysical account that Aristotle gives of perception shares some fundamental commonalities with the Heraclitean

[185b10, 186a11], eporegein [186a4]. He explicitly distinguishes all such psychological activities from acts of perception at $186 \mathrm{~d} 7-\mathrm{e} 2$.

${ }^{3}$ See $D A$ III $1425 \mathrm{a} 14-16$. While that list does not include time, Aristotle seems to indicate that time is a common object at De Memoria [DM] $1450 \mathrm{a} 9-15$.

${ }^{4}$ See especially DA III 1 425a30-b2; De Sensu [DS] 7 449a2-10.

${ }^{5} D S 7$ is given over to a discussion of the problems that confront any satisfactory account of crossmodal perception; it will be discussed in $\S 2$.

${ }^{6}$ On perceptual sophistication, see R. Sorabji 1995. 
view that Plato presents in Theaetetus. What, then, entitles Aristotle to think that perception alone can accommodate complexity ${ }^{7}$

According to the view defended below, Aristotle accounts for joint perception via the apparatus of metaperception. Aristotle would claim that I perceive a yellow, fluffy dog by virtue of having a single metaperception that combines the seeing of the color with the feeling of the fluffy fur. Although those qualities are generically different, Aristotle thinks that their being jointly actualized in a single activity is necessary and sufficient for their being jointly perceived, and, on my reading, he opens $D A$ III 2 by showing that a metaperception of those qualities will have the requisite numerical singularity.

But before we can consider the adequacy of this account, it is necessary to get the Platonic problem in view. To that end, I first turn to the theory of perception on offer in Theaetetus and its commonalities with Aristotle's own considered view. I conclude that Aristotle's account of perception is prima facie vulnerable to the Platonic conclusion; I then provide what I take to be his reply, found in DA III 1 and De Sensu [DS] 7. Next, I support my interpretation of the opening of $D A$ III 2 through consideration of its immediate context and the attendant aporiai. By the end of the paper, I hope to have shown that Aristotle has a substantive and parsimonious account of how the perceptual capacity, given its physical and formal limitations, is able to account for the richness of perceptual experience that joint perception requires. I will close with some remarks about the applicability of the metaperceptual framework to other activities of perception that go beyond the perception of the special objects by the special senses, but to fully explore the connection between those other activities, common sensing, and joint perception would go beyond the scope of the paper.

\section{A Problem: Theaetetus's Rejection of Unified Perception}

Theaetetus's final refutation of empiricism begins at $184 \mathrm{~b}$ with Socrates asking Theaetetus to be precise in the way he describes the relationship between the sense-organs

\footnotetext{
${ }^{7}$ Sorabji 1995: 195-196 and Gregoric 2006: 1-6 both stress the tension between the intellectualist conclusion of Theaetetus 184-186 and Aristotle's more wide-ranging conception of perception. McCabe 2007: 165-168 also compares Aristotle's position to that found in this section of Theaetetus, but, in accord with her general approach, her focus is on the origin of judgment.
} 
and the activity of perceiving: do we see with or through the eyes? What looks to be a trifling grammatical issue is, he insists, philosophically significant. Socrates is attempting to determine who or what, properly speaking, does the perceiving: do the organs (or the senses) engage in perception, such that we see simply when the relevant organ or faculty does? Or does perception require something beyond a functioning sense or sense-organ? If the former, disjoint special sensing exhausts our awareness; if the latter, sophistication enters into the system somewhere: there is a central unified faculty that takes our special sense perceptions as data.

The explanandum here is the unity of the perceiving subject. For, Socrates continues, if we perceive with the senses rather than through them, our experience will be like that of a Trojan Horse, wherein a seemingly single subject is actually several discrete ones. Since it is clear that our experience is not fragmented, it must be that our senses are somehow united within the soul. It is concluded that all perceptible objects will be cognized by or with that point of convergence rather than by or with the individual senses-though of course the senses themselves will play an important role, which Socrates describes by saying that the senses are instruments or equipment (organa) through which we perceive [184d4]. He concludes that the point of convergence is provided by the soul by itself [185e1-2], i.e., not through a sense-organ. While the perceptual data collected through the sense-organs will be the information that is manipulated by the soul by itself, the ultimate psychological account of the unity of perceptual experience will have to appeal to a non-perceptual capacity of soul. However, before Socrates can draw this conclusion, he makes a crucial assumption, which motivates the anti-empiricist conclusion. At 184e8-185a2, Socrates gets Theaetetus to agree that what is perceived through one sense is not perceived through another. What seems to be a fairly innocuous claim about the special objects — one can't hear colors - proves to be bolder and more far-reaching than it first appears. Socrates continues by observing that, given this constraint, the unified perception of two or more generically different objects is impossible. Specifically, he claims that while we think both a sound and a color have being (ousia) [185a8-9], their being cannot be perceived. ${ }^{8}$ Other common qualities that turn out, on

\footnotetext{
${ }^{8}$ Though it is clear that the conclusion of Plato's argument is that knowledge cannot simply be a matter of perception, exactly what notion of ousia is in play has been widely disputed. Cornford 1957 interprets it as a reference to Platonic Forms, a view that was refuted by Cooper 1970. Various
} 
this view, to be non-perceptible include the perception of sameness/difference that underlies joint perception and perceptual discrimination [185a11-12], number [185b2], likeness/unlikeness [185b4-5], beauty/ugliness, and goodness/badness [186a9]. None of these, Socrates argues, can be perceived [185e6-9], given the assumption that what is perceptible by one sense is not perceptible by another [185b7-9].

But while the premise that what is perceptible by one sense is not perceptible by another is plausible when restricted to the special objects, it becomes much less so when it is generalized to all possible perceptual objects. However, Socrates draws conclusions not just about the special objects, but also about our grasp of qualities like sameness and difference, so it is apparent that the premise applies more generally. ${ }^{9}$ This introduces a problem: why would Socrates think that all perceptible features work like the special ones? Though it does sound odd to say that one can feel a color, the same discomfort does not seem to arise with the claim that you can both see and feel shape.

Since Theaetetus accepts the premise without argument, we cannot look to the text to find the motivation. However, the principle can clearly be shown to follow from the theory of perception forwarded earlier in Theaetetus. According to that view, which Socrates describes as Heraclitean, everything is in constant motion. As such, perception too will be a kind of motion: it arises when active powers meet passive powers. As described in 156d3-

alternative interpretations have been offered: see especially Burnyeat 1976: 44; Burnyeat 1990: 5961; Cooper 1970; Kahn 1981; Modrak 1981. Fortunately, precisely what Plato has in mind when he employs ousia is not relevant in the context of this paper: what matters for my purposes is the inference from the fact that ousia is not specific to a special sense to the conclusion that it is not perceived at all.

${ }^{9}$ Burnyeat 1976 argues that Socrates only needs a weaker premise, to the effect that the special objects of different senses cannot be compared perceptually (see also Burnyeat 1990: 57). And indeed, Socrates opens with just such an example: it is not by sight or by hearing, he says, that we are able to compare a color with a sound (185a-c). However, contrary to Burnyeat, Socrates must be committed to the stronger claim that the senses cannot share any objects. The conclusion that Socrates draws is not merely that we cannot know by perception that the sense objects of two modalities are similar to or different from one another. Instead, he concludes that perception is never sufficient for knowledge (oud' ar' [metestin] epistêmês [186e7]), and this is so because perception cannot grasp the being (ousia) that underlies our ability to grasp truth. Thus, though the opening example involves a comparison of two sense objects, Plato is committed to the view that just as I cannot see that both a color and sound are, neither can I see that a color is. For if I could, then I could perceive (some cases of) being, and therefore (some cases of) truth, which would allow for (some cases of) knowledge by perception. 
$157 \mathrm{e} 7$, the force or process external to the perceiver is the active power that constitutes perception, and the perceiver's own (dynamic) sense-organ is the associated passive power. There are slow localized motions, which are processes that originate from the perceived object (active) and the perceiver (passive), and swift intervening motions, which move through the space between the perceiver and the external object. ${ }^{10}$

The result of this interaction, Socrates says at 156a7-b2, is a 'twin birth.' The intercourse of passive and active forces will produce yet another pair of forces: a perception, on the one hand, and the object of perception on the other. According to the Heraclitean view, a difference in the active and passive powers that meet will entail a difference in the product. For example, the products that arise from the intercourse between a white stone and an eye must be different from the products of that stone interacting with the skin, and this is so because the organs - skin and eye-are different. ${ }^{11}$ Since eyes and ears are themselves different, there can be no offspring that is the same for both, so there can be no shared perceptions. For the same reason, the common objects-objects which are supposed to remain the same regardless of what modality or modalities are perceiving them-must be denied existence as perceptible objects.

So if Heracliteanism is the right view of the metaphysics of perception, it is clear that the senses will only perceive their paradigmatic objects. ${ }^{12}$ That view of the domain of perception is too sparse for Aristotle's purposes. But there are reasons to think his view is

\footnotetext{
${ }^{10}$ Talk of objects is misleading if taken to imply stability over time: constant change precludes such objects. Though he acknowledges that he struggles with following the rule himself, Socrates says that one ought not to describe this picture using the verb-to-be: the 'state' of constant flux precludes any stability such as would be necessary for existence across any time whatever (157b-c)

${ }^{11}$ See also Theaetetus 156d3-6: "when, then, an eye and some other of the things commensurate with it which has come up to it, generate both whiteness and the perception naturally associated with it, things which would at no time have come to be if either of them approached something else" [emphasis added].

${ }^{12}$ Bernard Williams offers an alternative reading of Theaetetus, explicated by Burnyeat in his introduction to [1990], according to which the Heraclitean theory of perception is not accepted by Plato but is rather part of a reductio of Protagorean relativism. I will not address the alternate reading here: for the purposes of my argument it suffices to show that the claim that nothing is perceptible by more than one sense does follow from Heraclitean premises. I do not need to establish it as the only possible motivation, or even as Plato's motivation. As we will see, Aristotle accepts key parts of the Heraclitean picture, so he is prima facie forced into the conclusion that Plato draws here, whether for the same or different reasons.
} 
perilously close to that described in Theaetetus: Aristotle's metaphysics of perception shares some central features with Heracliteanism. First, Aristotle does accept the weaker form of the principle adduced at $184 \mathrm{c}$, according to which the special objects are not able to be perceived by the other special senses. ${ }^{13}$ While that weaker form was shown to be insufficient motivation for the wholesale rejection of empiricism ${ }^{14}$, it would nonetheless appear to make joint perception problematic. Joint perception requires the synthesis of discrete sensory modalities, which is seemingly precluded even by the weaker principle. ${ }^{15}$ Secondly, Aristotle's theory of perception says that one activity constitutes both the perceiving of an object and that object's being perceived [425b26-27]: where Socrates had a 'twin birth,' Aristotle has an only child. ${ }^{16}$ If Plato thinks that the interdependence that follows from a twin birth prevents the senses from sharing objects, then he will be wary of any position that permits shared objects yet claims an identity between the activity of the perceiver and the perceived. Given these similarities, then, and given the dialectical position Aristotle finds himself in as a student of Plato's, we would expect him to feel compelled to offer some account of how, contra Plato, unified perception is possible: how it is that a single perceptual activity can actualize multiple perceptual potentialities? Mere assertion will not suffice.

In what follows, I will argue that Aristotle does give such an account immediately following the introduction of joint perception and perception of the common objects in $D A$

${ }^{13}$ legô d' idion men ho mê endechetai hetera aisthêsei aisthanesthai (DA II 6 418a11-12).

${ }^{14}$ See fn. 9.

${ }^{15}$ In fact Aristotle further weakens the claim from DA II $6418 \mathrm{a} 11$ right before his discussion of joint perception, saying instead that the special senses perceive each other's objects coincidentally (ta $d$ ' allêlôn idia kata sumbebêkos aisthanontai hai aesthêsis [425a30-31]). Thus it is clear that Aristotle himself recognizes some tension between the weak principle and the possibility of joint perception. He goes on to elaborate on the way in which the special senses perceive each other's objects: not as they are individually but insofar as they are unified (ouk hêe $<>$ autai, all' $h \hat{e}<i>$ mia [425a31]). The account of their unity is the subject of the next two sections of this paper.

16 This is an instance of the Aristotle's general metaphysical account of activity and passivity, described in detail at Phys. III 3, according to which active and passive potentialities are jointly actualized within the passive agent. Marmodoro 2014 does not accept the standard interpretation of this passage: since she thinks actualities cannot actualize multiple potentialities, she has a different account (45ff). It might additionally be thought that since Aristotle defines potentialities in terms of actualities, it will not be possible for distinct potentialities to be jointly actualized. However, the parasitism of potentiality on actuality only necessitates that no two separate potentialities be always jointly-actualized. Aristotle clearly countenances multiple instantiations both via regular locutions like "one in number, different in being", and also at Physics III.3 202b8-10. 
III 1 and just before the introduction of discrimination at the end of III 2 . In the next section, I show that Aristotle thinks joint perception occurs if and only if there is a single activity of perception that actualizes diverse perceptual potentialities. Once that is established, I will argue that the reference to metaperceiving that opens $D A$ III 2 is meant to introduce the idea that, given Aristotle's underlying metaphysics of activity and passivity, it is entirely possible for a single activity of the perceptual faculty to actualize these myriad potentialities.

\section{Joint Perception}

Perhaps the most obvious way in which perceptual experience would be impoverished if we were restricted to special sensing is that we would no longer be able to have cross-modal perceptions. Instead, each modality would perceive discretely: we would, for example, see yellow, hear barking, and feel fur yet we would not grasp just through perception that all three qualities inhere in one and the same thing. Socrates describes this perverse possibility in Theaetetus by means of the analogy with a Trojan horse: if our access to the world were to stop at special sensing, our experience would be disjoint. There would be no single subject of those disjoint perceptions: since each Trojan horse is merely a container, the subjects would be as many and varied as the senses themselves. Fortunately it is evident that we have not suffered this cruel fate, so the senses must be centrally integrated. As we have seen, Plato has Socrates and Theaetetus conclude that the point of convergence is to be found in the soul 'itself by itself' (autê di' hautês), i.e., not through body parts, and therefore not through the senses.

Aristotle, on the other hand, views perceptual unity as a feature of the perceptual faculty. In $D A$ III 1, for instance, he describes a case where bitter, yellow bile is perceived. ${ }^{17}$ Here Aristotle is nearing the conclusion of his discussion of the perceptual part of soul. After reviewing the special senses, their special objects, and the media that physically underlie perception by the special senses, he turns to facets of perception that have not yet been addressed, including the perception of the common objects that he first introduced in $D A$ II

\footnotetext{
${ }^{17}$ Perceiving something as having multiple perceptible properties, at least in the sense Aristotle has in mind, does not require the possession of concepts of those properties any more than special sensing does. Just as I can see a yellow thing without having the concept $<$ yellow $>$, I can perceive a yellow bitter thing without having the concepts of $<$ yellow $>$ and $<$ bitter $>$.
} 
6. Unlike the special objects, which were already discussed in detail in later parts of Book II, the common objects are perceptible by multiple senses. The fact that these objects can be shared across the senses implies, according to Aristotle, that the senses are sensitive to each other's objects, which in turn requires that the senses themselves form a unity. As he puts it, 'The senses perceive each other's special objects coincidentally, not as they [the senses] [are] in themselves, but as a unity, when perception of the same object happens simultaneously, e.g. of bile that it is bitter and yellow (for it is not the task of another [perception] ${ }^{18}$ to say that both are one' [425a30-b3].

It will not be enough for Aristotle simply to assert that one can in fact perceive the sense-objects of different modalities as unified: given the objections found in Theaetetus, he will have to show how we grasp cross-modal sense objects in a way that does not require any capacity of soul beyond those provided by the perceptual faculty. In $D A$ III 1 's brief discussion quoted above, we see part of Aristotle's explanation of joint perception. Bile is perceived as both bitter and yellow in a single act of perception, which in turn requires that the senses themselves are fundamentally unified. In his much fuller discussion of joint perception in $D S 7$, he again observes that the senses must be one [449a8-9], and he provides more detail on how it is that the senses are able to act as one. This chapter, the closing one of De Sensu, examines how it is possible to perceive a complex-but-unified visual objectone that includes a variety of perceptible properties. Aristotle frames the discussion by asking 'whether or not one can perceive two things at once' [447a12-14]. His answer is in the negative, but as we have seen from the case of bitter, yellow bile, he does not deny the phenomenon that we would tend to describe in this way. While he rejects the idea that what is really being perceived is two or more things, he nonetheless does acknowledge that we are able to perceive a complex object in one and the same moment.

Indeed, according to Aristotle, it is precisely because there is only one underlying activity that the object is grasped as a single thing. The quotation from $D A$ III 1 - 'it is not [the responsibility] of any further [perception] to say that both are one'-evinces a

\footnotetext{
${ }^{18} 425 \mathrm{a} 31-\mathrm{b} 2$. The proper referent of heteras (another) is ambiguous. It is in the feminine, but beyond that the text does not specify what further thing is not needed. While I have chosen 'perception', it could also be taken to refer to the sense. Hamlyn 2002 uses 'perception' (which he argues for in Hamlyn 1968: 200), but Hicks 1907 and Ross 1961 choose 'sense'.
} 
commitment to the view that there being one perception is sufficient for there seeming to be one perception. For here something 'says' that the bitter and the yellow are one, and if it is not a further perception, it must be the same one. ${ }^{19}$ But $D S 7$ also argues the converse: there being a single perception is also necessary for there seeming to be one. Aristotle here claims, as I will show below, that if there are two or more numerically distinct perceptions, they cannot appear to be one, i.e., they cannot pronounce their object(s) as one. Thus, a perception's being numerically single is, for Aristotle, both necessary and sufficient for its appearing to be single.

Aristotle's argument in $D S 7$ depends on his claim that only one activity of perception can occur at a time. To this end, he first argues that simultaneous perception of special objects that are the same in kind is only possible insofar as they come together to form a mixture $[447 \mathrm{~b} 6-14] .{ }^{20}$ For, he says, if they are understood as discrete objects perceived simultaneously, their respective movements (kinêseis) would cancel each other out [447a29b6]. Next he claims that simultaneous-but-numerically-distinct perception is also impossible

${ }^{19}$ See also DS 7 447b24-25: "For we pronounce an object to be numerically one simply because it is simultaneously perceived."

${ }^{20}$ The contention that the special objects of one sense are only co-perceptible insofar as they form a mixture has been taken by some to mean that, e.g., black and white must unite to form a new color in order to be perceived together (see esp. Ross 1961: 229-230). We must bear in mind different kinds of mixture, though. One type of mixture, like a cake mixture, occurs when disparate elements irreversibly combine to form something new. We also talk, though, of mixing things by putting them in different structural combinations - combinations which may be reversible - as in a trail mix. LSJ supports this ambiguity: its second definition of meignumai is: "generally, join, bring together, in various ways". Aristotle's most systematic discussion of mixture is in Generation and Corruption I.10, where he says that the things that are mixed are not destroyed, but rather continue to exist in potentiality (327b23-5). Since Marmodoro 2014 has a largely physiological account of perceptual alteration, she understands this in the cake-mixture sense (219). To the contrary, I contend that his account suggests the trail-mix sense, and that the trail-mix view of mixture fits better with received facts about what it is possible to perceive (Lorenz 2009 interprets Aristotle similarly). On the narrower interpretation, I would be unable to see a chess board (Pavel Gregoric 2006's example (141)), since the black and white squares are not mixed in the former sense. It certainly seems improbable that Aristotle would be insensitive to the kind of perceptual object exemplified by the chess board. One may rightly describe the board as being made of two colors, just as one may distinguish the banana chips from the sunflower seeds in a bag of trail mix. Similarly, in the cross-modal case, one may break up the color of the tree from the feel of the bark. As we will see when we get to the conclusion of $D S 7$, each of these claims is true because the being of the components is different. Nonetheless, they are unified in the sense that all are parts of one unity, be it one bag of trail mix, or, in the perceptual case, one object of simultaneous perception. While the components of the latter have distinct potentialities, they are jointly actualized in a single activity of the perceptual faculty. 
in the case of perception of objects of different special senses: since objects of diverse genera are even more unlike each other than are contraries of a single genus, it follows that if the objects of one sense cannot be simultaneously perceived, then neither can those of different senses [448a13-19].

Indeed, for Aristotle, there are independent methodological reasons to reject multiple simultaneous acts of perception: since discrete-but-simultaneous activities would require distinct potentialities being actualized, this view would lead to an unacceptable multiplication of faculties. If I simultaneously-but-separately perceive two colors, for example, their being separate would require that different parts of me were responsible for each perception. ${ }^{21}$ Thus, I would have one part that potentially sees one color, and another part that potentially sees the other. Moreover, since that which has the potential to see white also has the potential to see black, it would follow that I have several specifically-identical but numerically-distinct faculties [448b22-25]. Such a view would clearly conflict with Aristotle's general commitment to parsimony in nature.

So simultaneous perception of multiple objects is not possible according to Aristotle, and this is so regardless of whether the objects are special objects of the same sense or of different senses. But couldn't it be that the objects are perceived discretely and only seem to be simultaneous? Aristotle goes on to consider this view, as exemplified by some (unnamed) students of music who claim that 'notes do not reach us together but only seem to do so, and that this escapes our notice by [occurring] over an imperceptible time' [448a20-21]. The idea behind this suggestion is familiar enough: what if we perceive a variety of objects at different times, which we then synthesize? While we clearly do not experience our perceptions as disjoint, isn't it possible that time does pass between different perceptions but the time lapse is so swift that we don't perceive its passage?

Aristotle rejects this view, for he claims that there cannot be imperceptible moments of time [448a24-30]. His argument here depends on the solution to Zeno's paradoxes that we find in Physics IV. There he says that while time is potentially infinitely divisible, it also exists as a continuum. As a continuum, all parts of it are perceived and no parts are

\footnotetext{
${ }^{21}$ These parts would not have to be spatially-divided; to call them 'parts' is merely a façon de parler.
} 
unperceived; accordingly, there are no imperceptible points in time. ${ }^{22}$ So since this rival explanation depends on the actual existence of imperceptibly short periods of time, it cannot get off the ground.

In any event, if Aristotle were to countenance the existence of multiple sequential perceptions, he would likely end up saddled with an intellectualist view like the one Socrates adopts in Theaetetus. If the activities through which we apprehend the whiteness and blackness of the chessboard were discrete, a separate account would be needed of our apprehension of the unity of the chessboard itself. Socrates is considering a similar problem in Theaetetus when he concludes that such apprehension requires an additional act of mind. Thus, Aristotle would not be likely to evade intellectualism if he went down the path that the musicians have trodden.

Given these considerations, Aristotle is drawn to the converse of his sufficiency claim from De Anima: if apparent simultaneity requires actual simultaneity, then the apparent simultaneity of joint perception will necessitate actual simultaneity. Since, moreover, Aristotle takes himself to have shown that only one perception can happen at any one time, it will follow that the perception that constitutes joint perception must be numerically single. ${ }^{23}$ It is a recurring theme in $D S 7$ that a unified and simultaneous perception asserts the unity of its object. At 447b14-15, for instance, he says "Therefore if the actual perception is a single one, the two objects will be pronounced to be one". ${ }^{24}$ Here Aristotle commits to the view that joint perception must take place at one time. And since, as he also argues in this

\footnotetext{
${ }^{22}$ Phys. IV.11, 218b27-9. Coope 2005: 37-41 denies that Aristotle should be interpreted as claiming that all passage of time is perceptible, but she also notes that this is the usual reading (40). Her argument against the default interpretation turns, moreover, on her claim that Aristotle is nowhere else committed to the impossibility of imperceptible time lapses. The present discussion-not mentioned in her book - explicitly expresses just such a commitment at 448a24-25 (oud' endechetai chronon einai anaisthêton oudena oude lanthanein) and 448b16-17 (hoti men oun outheis esti chromos anaisthêtos, ek toutôn phaneron).
}

${ }^{23}$ Marmodoro 2014 also says that joint perception (and discrimination) requires a single, unified activity of perception (190-193). She considers several models of how the common sense would be oriented to accomplish this and other of its functions and finds each wanting. She does not consider an account in terms of metaperception, likely because she does not interpret Aristotle's claim that perceiver and perceived are one in number as contending that there is one token activity that comprises both (see fn. 16), and so she would not see the metaperceptual account as providing for a single activity of perception.

${ }^{24}$ See also 447b24-5; 448a8-11. 
chapter, only one perceptual activity can occur at a time, it follows that joint perception must implicate exactly one activity. ${ }^{25}$

To be sure, joint perception will not have been explained unless my potential to perceive includes the potential to perceive complex tableaux in a single activity-not just specifically different across a single sense, but also generically different across multiple senses. Aristotle accounts for this in his typical style, viz. by ascribing the complexity to the sophistication of the perceptual faculty. He elaborates on his resolution at DS $7449 \mathrm{a} 8-20$, where he says:

It is necessary, then, that there is some one [faculty] of the soul by which it perceives everything, as said before, but [it perceives] different kinds through different [parts]. Is it that when actually undivided it is one thing that perceives white and sweet, but when actually separated two? Or does the position about the soul correspond to the one about the objects?for numerically one thing is white and sweet, and also many other things. For even if the affections are not separable from each other, each is different in being. The same should now be assumed concerning the soul: the sense faculty that perceives all is numerically one, but its being differs, in some cases generically and in others specifically. Thus [we] can perceive simultaneously with one and the same [faculty], but its account is not the same. (Translation from Ross 1955, with some modifications)

Here Aristotle considers two options, and he adopts the second alternative. He contends that his metaphysics, with its commitment to non-transcendent forms immanent in matter, explains joint perception in a way analogous to the way in which it accommodates unified mind-independent objects. In the case of a yellow, fluffy dog, the dog exists as a single thing, even though its perceptible qualities can be considered individually. What it is to be yellow is different from what it is to be furry. Nonetheless, the dog itself exists as a unity in a strong sense: it is one object. So while the potential to be furry and the potential to

\footnotetext{
${ }^{25}$ Gregoric 2006 makes a similar observation. As he puts it, "First, of an object which is one in number there is one act of perception [...] Second, in one act of perception the perceived object is pronounced to be one in number [...] Third, one act of perception occurs at one time, that is, at a time which is indivisible" (132). He describes these as corollaries that follow from the numerical unity of perceiver and perceived. On my reading, which follows the order of dialectic in DA III 1-2 425a30-426a1, the second condition follows from the first, and both set a prerequisite for an adequate theory of unified perception. The numerical unity of the activity of the perceiver and the perceived object is then brought in to satisfy that requirement.
} 
be yellow are generically different potentials, they are jointly actualized in the dog. As such, the dog is one in number, but multiple in account.

According to Aristotle, my perception of an object is single-but-complex in a way analogous to the way in which the dog is. Just as the dog has various physical characteristics, it also has various perceptual potentialities: the potential to be seen as yellow, to be heard barking, to feel soft to the touch, etc. These potentialities, which vary both specifically and generically, are jointly actualized in one perception. We can see, then, that joint perception in the case of an object requires no more than a numerically single perceptual activity that is subject to a complex description. ${ }^{26}$ The analogy with the dog makes clear that we are familiar with this type of complexity in other contexts: our perception of the dog as yellow and furry will be one to the same extent as the dog itself is. The dog is one thing that actualizes multiple potentialities. So too, my perception of that dog is also one in number but multiple in account. It is Aristotle's considered stance, then, that the perceptual faculty, like the dog, is fundamentally unified. It is not constituted by five discrete senses making up a mereological sum. As with a dog actively being perceived, these parts are not separable from the whole: in a case of joint perception, the perceived instance of yellow in the dog is not separable from its perceived fluffiness. Similarly, while what it is to be sight (and what it is to see) is different from what it is to be touch (and what it is to feel), sight and touch are numerically identical to each other and to the perceptual faculty as a whole: thus, while they are the same in number, they differ in account.

One may reasonably wonder how a single perceptual activity could include content from different modalities. Indeed, it is this concern that motivates the entire chapter of $D S$ under discussion. As we saw, the 'students of music' that Aristotle discusses at 448a19ff deny that it is possible and instead contend that there are discrete perceptual acts that take

\footnotetext{
${ }^{26}$ In order for the view to be plausible, Aristotle must not be thinking of physical change in the organs as constitutive of sensing, for in that case, given that seeing yellow and hearing barking depend on different parts of the body, they could not be identical. Nonetheless, rejecting that constitution claim does not commit Aristotle to denying the presence of any physical change in the organ. In fact, a qualitative alteration of the organ could be correlated with an act of perception. Further, given our particular material constitution, that alteration may prove to be a necessary condition for a successful perception. Thus, my reading can afford to remain neutral as to whether there are any physiological changes during perception for Aristotle, though it is committed to denying that any such alteration just is the act of perceiving. For a discussion of the controversy, see Burnyeat 1995a; Burnyeat 1995b; Burnyeat 2001; Caston 2005; Johansen 2007; Sorabji 1975.
} 
place at imperceptibly different times. In response to that view, Aristotle rejects the possibility of imperceptible time differences, and so he claims that any perceptual content that seems to have been perceived simultaneously is in fact perceived simultaneously. Moreover, since Aristotle contends that only one perceptual act can occur at a time, it follows that simultaneous perception must also be numerically singular. Of course a numerically single perception, which represents its complex object as unified, must further represent that object as a complex one. For example, when I perceive a dog, I perceive it as one thing, but one thing that has many generically- and specifically-different qualities. How it is that Aristotle thinks he is entitled to permit perceptual activities that are one in number but instantiate numerous potentialities has yet to be seen, but that such unity is possible in the non-perceptual case has already been established by the case of actual mind-independent objects. We can conclude, then, that the possibility of joint perception requires that the perceptual faculty be somehow able to engage in numerically single perceptual activities with complex contents. What remains to be explained is how it is possible for a single activity to actualize those multiple perceptual potentialities. If Aristotle can accommodate that possibility without going beyond the framework provided by his general account of perception, then he will have shown that the perceptual capacity alone suffices for joint perception, contrary to Plato's conclusion in Theaetetus.

\section{How is Joint Perception Possible? The Metaperceptual Account}

The Joint Perception Reading of DA III 2 425b12-17

Aristotle's account of joint perception will have to proceed via the positing of a numerically single activity that actualizes diverse potentialities. But we also saw that Plato, through Socrates, questions whether perceptual unity is even possible. For if, as Plato thinks, perception relies heavily on the relationship between the sense and the external object that causes the perception, it will be prima facie unlikely, maybe even impossible, for distinct 
types of perceptual potentialities to be jointly actualized. It is incumbent on Aristotle not just to claim that we engage in joint perception, but also to explain how we do so. ${ }^{27}$

I argue that Aristotle accounts for the possibility of joint perception via the invocation of a metaperceptual apparatus. Just a few lines after discussing the unified perception of bitter, yellow bile, he opens $D A$ III 2 with the following observation and its attendant aporiai: [Joint Perception [JP]]: [A] Since we perceive that we see and hear, it is necessary [that it is] by sight that one perceives that one sees or by another [sense]. [B] But [then] the same [sense] would be of sight and of the color that is the subject [of sight], with the result that either there will be two [senses] for the same thing, or [the sense] itself will be of itself. [C] Yet if the sense for sight were indeed different [from sight] either there will be an infinite regress or some sense will be of itself. So we should admit this of the first [in the series]. (425b12-17, Hamlyn 2002 translation, with some modifications)

My reading of this passage, which I call the 'Joint Perception Reading' or 'JPR', interprets Aristotle as invoking joint perception at [JP:A]. In contrast, traditional readings take it that Aristotle is here referring to conscious awareness. I call all such readings 'Awareness Readings', abbreviated 'AR'. ${ }^{28}$ The differences among AR accounts, though substantial, are orthogonal to my criticism, which turns on one thing they all have in common, viz. that by invoking an opaque context, they are unable to motivate the aporiai. ${ }^{29}$

\footnotetext{
${ }^{27}$ The problem is more severe if the relation turns on physiological facts about the organ, as it seems to for Socrates in Theaetetus, but it is present even if we take a more circumspect view about the role of the organ in perception.

${ }^{28}$ Arguments for versions of AR are given by Aquinas 1999; Caston 2002; Hicks 1907; Johansen 2002; Kahn 1975; Kosman 1975; and Osborne 1983. Kosman takes pre-reflective self-consciousness to be at issue, while Caston takes it to be awareness of the experience. Johansen, on the other hand, understands Aristotle to be concerned with reflective self-consciousness. Osborne might be thought to be an exception, since she takes the explanandum to be our awareness that we are seeing as opposed to hearing, but note that this is still a form of awareness, albeit one that has not engaged many contemporary philosophers of mind. Gregoric 2006 takes a similar line, reading the passage as concerned with awareness of the whether the senses are in operation, as does Polansky 2007, who describes the explanandum as "self-awareness of the senses" (380). Marmodoro 2014 translates aisthanometha in this passage as 'we are aware', and implies that she takes self-awareness to be at issue (196). AR is assumed by Alexander of Aphrodisias, Quaestiones; Everson 1997; Kahn 1975; and Modrak 1987.

${ }^{29}$ I will not be addressing in detail McCabe 2007's view, which agrees with mine in denying that consciousness is the explanandum of the passage but is otherwise significantly different. On her view, Aristotle brings up higher-order perception not as a gloss on consciousness but because he is trying
} 
The popularity of AR is easily explained: to contemporary ears steeped in higherorder views of consciousness, the claim that we perceive that we see and hear is naturally read as invoking the phenomenon of consciousness. But perceptual consciousness was not a topic of philosophical analysis in Aristotle's time, and I argue that [JP:A] could equally well be a gloss on joint perception of an object. To illustrate, let's take our standard example: my perception of a dog. This perception includes an array of perceptual information. What requires explanation is how I am able to be aware of this array as a unitary phenomenon. Aristotle's answer to this question, I argue, is that the perceptual faculty, in addition to perceiving those shapes, colors, sounds, etc., also has the potential to perceive those individual perceptions. I undergo countless seeings of diverse colors as well as hearings of particular sounds, and so on. But I also unite those perceptions in a single unitary act, an act that must itself be a perception if Platonic intellectualism is to be avoided, and which therefore ought to be described as a perception of my seeings and hearings. ${ }^{30}$

So interpreted, the opening of $D A$ III 2 should be understood as alluding to any of the following: (1) 'Since we perceive that the dog is yellow and barking'; (2) 'Since we perceive that we see and hear the dog; or, more generally, (3) 'Since we perceive an object as a unity of distinct perceptible properties.' Given, as I argued above, that Aristotle believes he can account for joint perception iff there is a single perceptual activity that has a complex content, JPR predicts that Aristotle will invoke a numerically single state here as well. In other words, if JPR is right to take the reference to metaperception as an appeal to the general phenomenon of joint perception, then the solution Aristotle will give to the aporiai should be expected to

to argue that perception can be transitive, contra Charmides. Once it is seen that perception can be transitive - and, it turns out, reflexive - this allows for us to judge (krinein) by perception, which then allows for a variety of perceptual activity. Though joint perception is among the activities in question, McCabe mentions it only in passing and always in a list of other examples. She also explicitly suggests that the variety of activities in question will not have much to unite them $(163$, passim), whereas I expect that joint perception and other activities will have a great deal in common -in fact, all will rely on metaperception, and will be activities of the common sense. I will not be able to establish the latter point in this paper, but for some of the central motivation, see $\S 4$.

${ }^{30}$ It might be thought that joint perception requires a perception of the colors and sounds as one rather than a perception of the perception of the colors and sounds as one. However, recall that what is being explained is the unity of perception, not the unity of the objects of perception. If I am to have a single perception of a multi-faceted dog, it is crucial that my perception of its colors is the same activity as my perception of its sounds, and so on. 
invoke the same numerically single activity as that mentioned in the previous chapter of $D A$ and in $D S 7$. And indeed, as we will see below, $D A$ III 2 goes on to do just that.

I will defend JPR in the next few sections. First, I show that JPR provides a better motivation than AR for the aporiai taken to follow from the fact that we perceive that we see and hear. Second, I show that Aristotle's resolution of those aporiai appeals to the same consideration, viz. token identity, as I have argued is required for the explanation of joint perception. Third, I briefly argue that it is anachronistic to expect Aristotle to have a concern with conscious awareness. I conclude that the metaperceptual apparatus described in $D A$ III 2 is offered as a way for Aristotle to account for the possibility of joint perception, in spite of Plato's reservations. As such, it is a crucial part of the defensibility of Aristotle's picture, a fact that is missed when the reference to perceiving that we see and hear is taken to designate consciousness. The metaperceptual account likely has applications to other complex perceptual activities, which I will touch upon in the closing section.

\section{$J P R$ and the aporiai}

A broad concern with joint perception can motivate the aporiai that follow [JP:A]. AR's account of the motivation of those aporiai is less successful, especially in the case of the second, which gives JPR a distinct advantage. The first aporia is labeled '[JP:B]' above, and reads as follows:

[Since we perceive that we see and hear, it is necessary that it is by sight that one perceives that one sees or by another sense.] But [then] the same [sense] would be of sight and of the color which is the subject [of sight], with the result that either there will be two [senses] for the same thing, or [the sense] itself will be of itself.

Aristotle is here concerned with the faculty that is involved in the metaperception. If it is sight that sees what is seen, then sight will have to see itself, but if it is not sight, then both sight and some other sense will perceive the color. ${ }^{31}$ This latter possibility seems to be

\footnotetext{
${ }^{31}$ Caston 2002 disagrees with orthodoxy, adopting what he calls an 'activity reading' of passage [JP], according to which Aristotle is concerned not with the number of senses implicated, but, instead with the number of states. We will see in the next section that Aristotle resolves the aporiai by positing a single activity that includes both the lower-order perception and the metaperception, so JPR can remain neutral as between these rival readings.
} 
precluded by $D A$ II 6, where Aristotle introduces the special objects as those which are unable to be perceived by any other sense (418a11-12).

According to JPR's understanding of the explanandum, it is obvious that the metaperception must contain the content of the lower-order perception. JPR interprets Aristotle as seeking an explanation of the unified perception of the various perceptible properties possessed by, e.g., a dog, so any adequate explanation will have to contain those properties. If the metaperception does not include the perception of the shapes, colors, and sounds of the dog, it will not provide any sort of account of the unified perception of those shapes, colors, and sounds. Just as the account of seeing has to include reference to color, so too the account of joint perception must include reference to the percepts. The connection is so obvious that it doesn't demand defense-which is why Aristotle doesn't provide any.

However, AR theorists have found the assumption that the metaperception will also take on the object of the lower-order perception to be more problematic. As Hamlyn puts it: It is not clear why Aristotle supposes this consequence to follow. He seems to assume that if I perceive by sense $\Upsilon$ that I see X, I must therefore perceive X by $\Upsilon[\ldots]$ [O]ne can clearly be aware that one is seeing without being aware of what one is seeing. (Hamlyn 2002: 112.) Notice that Hamlyn's worry trades on understanding the explanandum of this section to be reflective awareness, leading him to take the introspectively-accessible fact that I can be aware of a perception without being aware of what it is a perception of as evidence that Aristotle is making an error here.

Faced with this difficulty, AR theorists have attempted several accounts of the motivation for the aporia. First, it has been observed that the aporia is reminiscent of a claim in Charmides. ${ }^{32}$ At $167 \mathrm{c} 8-\mathrm{d} 3$, Socrates challenges Charmides's claim that sophrosyne is simply self-knowledge — knowledge of knowledge and nothing else — by asking whether in an analogous case there could be vision that sees itself but doesn't see color. It is accepted by all parties in the dialogue that this would be absurd, and so it is concluded that sophrosyne cannot be this empty kind of self-knowledge.

I don't object to the claim that there is an allusion to Charmides here. But the similarity between the two cases cannot adequately motivate the aporia. To see this, recall

\footnotetext{
${ }^{32}$ Caston 2002: 772; Gregoric 2006: 176; Hicks 1907: 434; Johansen 2012: 188; McCabe 2007: 155ff; Sorabji 2006: 202.
} 
the dialectical structure of De Anima. When the aporia is introduced, Aristotle has yet to conclude that the sense is reflexive: that conclusion awaits the resolution of the second aporia. As such, Aristotle has not established that whatever it is that perceives vision must itself be a type of vision. The worry in Charmides about how a faculty can be of itself, though, trades on just such reflexivity. Plato does not express a general concern with the idea that an arbitrary faculty could grasp seeing but not color. The problem is that sight cannot perceive itself without seeing color. This follows, as Sorabji notes, because if there is no perception of color, we do not have an instance of seeing. ${ }^{33}$ But the objection only shows that you can't see sight without seeing color, not that you could not otherwise grasp sight without grasping color. So if Aristotle has yet to conclude that it is sight that (in a way) sees that it sees, then the Charmides worry cannot yet arise.

Other commentators attempt to account for Aristotle's first aporia by appealing to his later claim that the actuality of the sense-organ is identical to that of the sensed object. ${ }^{34}$ If the perception itself is constituted by the actuality of the sensed object's potential to be perceived, then perceiving the perception will be the same thing as perceiving the actuality of its object. This response appears inadequate, though, for Aristotle does not express a commitment to this identity until several Bekker lines after the aporia. ${ }^{35} \mathrm{JPR}$ proposes that

${ }^{33}$ Sorabji 2006: 202. Polansky 2007 motivates the aporia this way: he says that since color is the hupokeimenon of seeing, it must similarly be the hupokeimenon of perceiving seeing (381-382). And indeed, Aristotle defines the senses in terms of their objects, which tends to support the idea that all seeing ineliminably implicates color. Alexander of Aphrodisias has such a view; he says: "for seeing is nothing other than being in activity by sight concerning visible objects" (ou gar esti to horan allo ti hê energein têi opsei peri ta horata [Quaest. 3.7, 92.6-7]), and if this is to motivate the first aporia, ta horata must be interpreted as referring specifically to colors. It is clear that Alexander expects to be so interpreted, since his immediately preceding sentence asserts that the activity of seeing is about colors (peri ha hê energeia hê kata to horan, esti de tauta ta chromata [Quaest. 3.7, 92.5-6]). For more on Alexander in this context, see Caston 2012.

${ }^{34}$ Gregoric 2006: 178; Johansen 2002: 9; Johansen 2005: 243; Kosman 1975: 514; McCabe 2007: 148n31; Modrak 1987: 66; Osborne, 1983: 403-404. Kosman takes the aporia to follow only for the second disjunct; that is, he says that only if another sense is responsible for the metaperception will it follow that that sense will take as its object both sight and the lower-order perceptual object (500), whereas Johansen (8) and Osborne (401) both take the aporia to follow no matter what faculty is responsible for the metaperception.

${ }^{35}$ Also, the identity Aristotle proposes later on in III 2 is identity in number, not in being. Since the AR view takes the metaperception to explain awareness, and awareness introduces an intensional 
we read that subsequent commitment as a response to a general worry about the multiplication of states that would seem to follow from the metaperception in question. To the extent that it is preferable to interpret subsequent claims as resting on prior ones rather than the other way around, then, JPR has a superior account of the first aporia.

Victor Caston offers a third explanation of the first aporia. He argues that while Hamlyn is right to insist that we could be self-conscious without being aware of the content of our perceptually conscious states, such a possibility is beside the point. If we understand [JP] as attempting to provide an explanation of perceptual consciousness rather than selfconsciousness, it will follow that the contents of lower-order perceptions will have to be constituents of the metaperception (Caston 2002: 771). This is, I think, the most promising avenue for AR to take. It is similar to JPR's account in that it holds that what Aristotle is explaining here necessitates, in a straightforward sense, that the lower-order content be taken on by the higher-order perception. ${ }^{36}$

Recall that, according to JPR, the first aporia follows from the fact that Aristotle is providing an account of the perception of similarity and difference: we cannot engage in joint perception without perceiving those things that are joined. Caston's account here proceeds in a similar fashion, for we also cannot consciously see red without being conscious of the red. Accordingly, there is no decisive objection to this way of motivating the first aporia. I argue, though, that JPR is preferable to Caston's account in that it provides continuity with the discussion of joint perception from $D A$ III 1 and does not ascribe a seemingly anachronistic interest in consciousness to Aristotle. ${ }^{37}$

JPR has a more distinct advantage over AR in motivating the second aporia. It is labeled '[JP:C]' above, and reads as follows:

framework, it would seem identity in being would be necessary to motivate the worry AR theorists think Aristotle is expressing here. Caston 2012: 46 directs a similar objection at Kosman's view.

${ }^{36}$ See also Kosman 1975: 512.

${ }^{37}$ Johansen 2012 argues that Aristotle must think the metaperception will take on the lower-order perception because of his particular views on the metaphysics of perception: "Perception, Aristotle explained, occurs when the sense-faculty takes on the sensible form of the sense-object. Therefore one cannot perceive the perception of that sensible form without also perceiving the sensible form as it is taken on by the sense-faculty" (187). His second sentence begs the question, however: why should perceiving our perceptions require perceiving the perception of that sensible form? The appeal to his formula for perception is not to the point in addressing that question. 
[Since we perceive that we see and hear], if the sense for sight were indeed different [from sight] either there will be an infinite regress or some sense will be of itself.

While Hamlyn's commentary claims that this aporia is 'better' (122), it too stands in need of motivation. First, notice that no regress threatens unless it is a necessary fact that we perceive our perceptions. If we 'just so happen' to have a perception that we see and hear, there will be no reason to expect a perception of our perception that we see and hear, much less a perception of our perception of our perception that we see and hear. Of course Aristotle must resolve this aporia by denying that a regress actually does ensue (regresses are to be avoided, after all), which he does in the next line. But why does he think there is a threat of regress in the first place? A regress only threatens when the existence of the thing in question (in this case a psychological state) requires another thing of the same kind, which in turn requires yet another, and so on. ${ }^{38}$

For example, the regress regarding wishing that opens Nicomachean Ethics (1094a18-21) only threatens because of Aristotle's antecedent commitment to the claim that, of necessity, everything we wish is wished for the sake of something. Clearly we must also wish the end that our wish is for the sake of. So, for example, if I wish for X, I must wish it for the sake of something, say Y. Since I also wish for Y, I must in turn wish it for the sake of something, and so on.

Applied to the case at hand, then, no regress threatens if it is merely a contingent fact that we perceive that we see and hear. In other words, the threat of a regress is predicated on the presupposition that all perceptions, not just lower-order seeings and hearings, must themselves be perceived: in order for the perception to exist, it must rely on another thing of the same type, i.e. another perception. Why would Aristotle assume that all perceptions must themselves be perceived?

JPR again provides a straightforward justification for this assumption. Since our perceptual experience of the world always implicates unified perceptual activities such as joint perception, this metaperceptual apparatus must operate whenever we perceive. But if

\footnotetext{
${ }^{38}$ Johansen 2002 sees regress as a problem even though he interprets Aristotle as thinking that the metaperception is contingent. In reply, Kosman 2007 contends that the regress requires more than mere contingency (See also Kosman 1975: 501). McCabe 2007 also argues that a faculty reading (see Caston 2002) can motivate the regress even if the point is only that each perception is perceivable (i.e. even if it is not the case that each perception is actually itself perceived) (151-3).
} 
there were multiple simultaneous activities of the apparatus, the metaperception would not provide the requisite unity and our experience would be disjoint, which would introduce the need for another higher-order perceptual state that unifies these disparate activities, and so on.

But while the necessity of metaperception follows straightforwardly from JPR, AR theorists face considerable obstacles. In fact, the very reasons one might have for adopting a metaperceptual account of conscious awareness tell against claiming that all of our perceptions must themselves be perceived. To see this, recall that AR views, despite substantial disagreement on the details, hold that the metaperception is the mechanism by which we are made aware of some particular perception, a perception that would not otherwise be conscious. ${ }^{39}$ According to the AR view, then, Aristotle is concerned in this aporia with cutting off a regress that would effectively make us aware of an endless series of nested perceptual states. Furthermore, since Aristotle must think that the metaperception is necessary in order to get the regress worry going, he must be interpreted as assuming that being aware of any perception would somehow require us to be aware of these endless states. The implausibility of such a conclusion undermines the reasonableness of the initial assumption: why wouldn't Aristotle choose to deny that every perception must itself be perceived rather than accept the possibility that the regress opens up?

Caston suggests that while we can find no compelling independent reason for the worry, it is clear that Aristotle is committed to the general principle that we perceive all of our perceptions. In any event, he says, 'Aristotle may view it ... as an acceptable generalization of the opening of the chapter, when he claims that we perceive that we see and hear' (2002: 774). For support Caston turns to Nicomachean Ethics IX 9 1170a29ff, where Aristotle claims that there is something in us that perceives all of our activities. Caston does not himself endorse the generalized claim (indeed, he notes that it is 'obviously controversial' (2002: 775)), but he takes the Nicomachean Ethics passage as sufficient evidence that Aristotle would accept the premise.

\footnotetext{
${ }^{39}$ If it were thought that the perception would be conscious even if it were not the subject of a
} metaperception, then that metaperception would not explain our conscious awareness of it. 
The first claim Caston makes here - that it is an acceptable generalization-has already been addressed. For while it may at first have struck Aristotle this way, the absurdity of accepting it in its general form ought to have led him to reject it. ${ }^{40}$ On the contrary, it must be that Aristotle is independently committed to the principle. That commitment is sufficiently motivated by JPR: joint perception requires that a single perceptual state actualizes all of the contents that are perceived jointly. If there were multiple states, they would need to be joined by a further perception of those (distinct) perceptions - and then that perception would have to be numerically singular. The metaperceptual apparatus must bottom out in a single state that perceives itself: insofar as that state is meant to supply unity, a regress threatens until that unity is achieved.

It certainly is true, as we have seen, that Aristotle thinks that we perceive all of our perceptions, and the Nicomachean Ethics passage further illustrates that commitment. But I suggest that it is Aristotle's adoption of the necessity principle in DA III 2 that motivates his broadening of that principle in Nicomachean Ethics - not, as Caston would have it, the other way around. Indeed, I take the Nicomachean Ethics passage as providing further support for JPR, for it is yet another instance where metaperceptions are invoked in order to account for a kind of psychological unity. ${ }^{41}$

Accordingly, while in some of its forms AR is able to motivate the first aporia, it is unable to motivate the second. Since both aporiai clearly follow if Aristotle is concerned with joint perception rather than consciousness, we ought to read him as being so motivated.

\footnotetext{
${ }^{40}$ In addition, note that as a generalization it seems false. As Plotinus observes, we are not always conscious of engaging in psychological activity (Enneads 1.4 10,21-29): while it seems plausible to suppose that when awake we are always perceptually conscious, it is much less reasonable to assume that we are always reflectively-conscious. But if that is right, then we have subjective grounds for rejecting the necessity claim-grounds that are, moreover, independent of the dialectical ones adduced above.

${ }^{41}$ For more on other passages seemingly related to the opening of $D A$ III 2 , see $\S 4$.
} 


\section{The Resolution of the aporiai}

At the end of [JP], Aristotle concludes that since some sense must perceive its own activity, it is best to claim that the initial sense does so. But Aristotle's view is not quite so straightforward, as is clear when he elaborates on his position using the example of sight: But this presents a difficulty, for if to perceive by sight is to see, and if one sees color or that which has color, then if one sees that which sees, that which sees primarily will have color. It is clear then that to perceive by sight is not one thing, for even when we do not see, it is by sight that we discriminate darkness and light, though not in the same way. (425b17-22)

It is by sight that we perceive darkness, but it is not by seeing. When one perceives darkness, one is not, it seems, seeing any color at all. Yet clearly one's perception of darkness (or light) is dependent on the capacity for sight more than it is on the capacity for, say, hearing. So too with metaperceiving: perceiving yellow, bitter bile is dependent on sight and taste more than on any other perceptual (or non-perceptual) capacity. As Aristotle resolves the aporiai, he notes that perceiving that I see is not just the act of perceiving color, for it is also, at a minimum, perceiving the activity of the sense itself. As in the case of perceiving darkness, the fact that the metaperception takes in something other than color means that it is not merely the special sense doing its paradigmatic work. Nonetheless, the perception that I am seeing is dependent on the sense of sight, and as such, it is correct to say that perceiving that I see is a product of sight, even though it is not strictly an act of seeing. The upshot of this conclusion, according to JPR, is that the activity of the five senses suffices for the possibility of joint perception: as he puts it in DA III 1, "there is no other sense besides the five [special senses]" [424b22].

In the long passage from $D S 7$ quoted above (449a8-20), Aristotle says that joint perception implicates only one faculty, which may initially be thought to be in some conflict with the conclusion here. But, as he also stresses there, the account of that faculty will not be univocal: he concludes that "[we] can perceive simultaneously with one and the same [faculty], but its account is not the same" [449a19-20]. There will be separate accounts of each sense, and those accounts, given in $D A$ II 7-11, will make reference to the special objects of each sense, the organs used, and the relevant media. As he resolves the aporiai of [JP], it becomes clear that while the accounts of the individual senses do not refer to their role in 
joint perception, the senses can and do participate. Since joint perception is no part of the account of each sense, though, the activity of joint perception is not felicitously described as an activity of seeing, or of hearing, and so on. Nonetheless, joint perception is ontologically reducible to activities including seeing or hearing - that is, it is nothing over-and-above seeings and hearings. ${ }^{42}$ We have, then, an account of how the senses can converge without requiring a distinct sixth sense, and that account proceeds via the invocation of a metaperceptual apparatus.

So unified perception does not require a sixth, emergent, sense. But that conclusion does not allay all concerns about joint perception. For as discussed above, joint perception also depends on there being only one activity. As such, the claim that sight in a way perceives that it sees needs to be supplemented with the further claim that it perceives that it sees in the very same activity as it does the lower-order seeing. This introduces a further problem: how can it be that metaperceptions are identical to their lower-order counterparts? Initially, it would seem that perceptions of our perceptions would be numerically distinct from those perceptions themselves; yet if Aristotle is to provide an explanation of joint perception, then he has to reject that appearance. ${ }^{43}$ And indeed he does just that, for his very next point is that the activity of the sense is the same activity as that of the object that is sensed (425b26-27). In this way, then, the perception of my seeing will be numerically identical to the seeing

\footnotetext{
${ }^{42}$ In his discussion of $D S 7449$ a5-20, Gregoric says that the common capacity "emerges from the unity of the perceptual part of the soul" [Gregoric 2006: 137-8, emphasis added], but he gives no argument that it is an emergent quality. In fact, since Gregoric calls this passage "the solution to the problem of simultaneous perception" (135), and since Aristotle here claims that the perceptual faculty is one in number and divided only in account, Gregoric ought to take it that the unity of the perceptual part of the soul just is the solution, not that the unity underpins a separate capacity not possessed by the senses themselves.

${ }^{43}$ Indeed, the Commentators were known to object to the idea that a sense can perceive itself precisely by denying that a sense can get the proper remove from itself. This was thought to be true in virtue of the bodily nature of the senses, and the inability of a spatially extended thing to stand at a remove from itself. See, for instance, [Philoponus] De An. 466,18-29; [Simplicius] De An. 173,3-7. Aristotle would presumably deny that both the sense itself and its activity are bodily: while the sense relies on an organ, that organ is not identical to the sense. Similarly, in the activity of perception, the organ might undergo some qualitative alteration, but that alteration shouldn't be understood as constitutive of perception. Both of these claims are controversial; see the references in fn. 26. In any event, Aristotle does not seem to have considered this type of objection.
} 
itself, and also to the being-seen that attaches to the perceptible object. ${ }^{44}$ Thus, the resolution of the aporiai is able to explain how perceptual complexity is possible-how it is that one perceptual activity is able to actualize multiple perceptual potentialities. On Aristotle's view, one activity can be described variously as the seeing of yellow, the tasting of bitter, and the perceiving of the seeing of yellow and tasting of bitter, and the singleness of the activity accounts for the unity of the perceptual contents. ${ }^{45}$

\section{JPR and Consciousness}

We have already seen that AR has difficulty motivating the aporiai that follow from our master passage [JP], but a more general problem with its claim that consciousness is the subject of that passage is its anachronism. While state consciousness as a phenomenon has a long history of recognition in philosophy, as a problem it is not prominent in the classical period. ${ }^{46}$ Aristotle does arguably acknowledge conscious awareness in a variety of places, but he does not seem to think that it introduces any added difficulties. In Metaphysics $\Lambda .9$, for instance, he says that knowledge, perception, and thought are 'about themselves on the side' (autês en parergôi) [1074b36]. More explicitly, in Physics VII 2 244b15-245a1, Aristotle notes that animate creatures, when altered in respect of the senses, are not unaware of being affected (to [d'] ou lanthanei paschon), and he goes on to claim that such creatures may be unaware of being affected if those affections are not alterations by means of the

\footnotetext{
${ }^{44}$ That is, given the transitivity of numerical identity, if the perception and the perceived object are jointly actualized, and the perception of the perception and the perception are jointly actualized, then the perception of the perception and the activity of the perceived object are also jointly actualized.

${ }^{45}$ Contra Marmodoro 2014's reading, which holds that there are two separate activations - one the activation of the potential of the perceiver and one the activation of the potential of the perceivedwhich Aristotle calls one activity only because they are mutually dependent, simultaneous, and covary (94). This is a corollary of her reading of Physics III.3, see n. 16.

${ }^{46} \mathrm{My}$ focus in this section is on perceptual state consciousness. Certainly there is no precedent in Plato for viewing state consciousness as a problematic feature of psychology. See Hardie 1964; Kahn 1975: 22-3; McCabe 2007: 146-7. Creature consciousness is similarly not taken to be a problem: living and non-living things are distinguished by whether they possess a soul, and while living things like oysters are not sophisticated, there is no suggestion that they might lack basic awareness. Selfconsciousness and the joint awareness of perceptions and thoughts together may raise special problems, which Aristotle discusses in NE IX. 9 117025ff, again invoking a metaperceptual apparatus.
} 
senses. The introduction of modality in the latter case-non-perceptual alteration may escape our notice - suggests an inverse commitment in the former case: perceptual alteration must not escape our notice. Thus, it would seem, Aristotle thinks of awareness of a perception as a necessary condition for its being a perception in the first place.

In a much-discussed passage, $D A$ II 12 424b16-18, Aristotle asks what constitutes smelling beyond its being an affection ( $t i$ oun esti to osmasthai para to paschein ti;). He presents one (and only one) possible answer, viz. that smelling is perception ( $\hat{e}$ to osmasthai aisthanesthai) ${ }^{47}$ Given that the Physics passage above distinguishes perceptual affections from non-perceptual ones in virtue of the fact that the former do not escape our notice, it would seem he is here indicating that the difference is one of awareness; smelling is not a mere affection because we are aware we are smelling. Moreover, Aristotle seems to think that describing smelling as a perceptual affection suffices to distinguish it from nonconscious types of affection. Since he takes this response as an adequate answer to the underlying question, it is unlikely that he thinks of consciousness of our perceptions as an additional fact over-and-above their being perceptions. As such, we have grounds to conclude that his account of perception just is an account of conscious perception; there is no reason to think that Aristotle views perceptual consciousness as a distinct phenomenon that stands in need of its own account. Indeed, the only passage where he is even alleged to give an account of awareness is the passage in question, and, I have argued, there is no compelling reason to read the $[\mathrm{JP}]$ in this way. ${ }^{48}$

\section{Common Sensing and Other Activities of Complex Perception}

I have limited myself here to an extended discussion of joint perception. I do this because it is this phenomenon Aristotle has immediately in mind when he introduces the metaperceptual apparatus in $D A$ III 2, and because between there and $D S 7$ he says (comparably) a lot about the topic. However, joint perception is not the only instance of complex perception, i.e. of perception that goes beyond the reception of the special objects

\footnotetext{
${ }^{47}$ Or, accepting Torstrik's emendation, ê to osmasthai kai aisthanesthai.

${ }^{48}$ According to [Simplicius] (De. An. 188,4-5), Aristotle thinks that perceiving that we see and hear is a consequence of consciousness (ek tês hêmeteras sunaithêseôs), not the cause.
} 
by the special senses. If Aristotle is to defend the completeness of his theory of perception, all such activities must be explicable in terms of the activity of the five senses. We have already seen that metaperception does not require invoking any additional sense, so it would be parsimonious to give a similar account of other instances of complex perception. And in fact, if we look at his discussions of things like perceptual discrimination and sleep, we do find a similar response.

In De Somno (DSV) 2, for instance, Aristotle finds himself appealing to a metaperception in the context of another unified perceptual phenomenon-in this case perceptual discrimination $^{49}$ - and he again draws the conclusion that the senses do not engage in these activities in virtue of being the particular senses they are, but, rather, in virtue of the element common to each of them. There he says:

[A] Since each sense has something special and something common - for example, seeing is special to sight, and hearing to the sense of hearing, and the same way for each one of the other [senses] [B] there is some common potentiality accompanying all of them by which one also perceives that he sees and hears [C] (for of course at any rate it is not by sight that one sees that one sees, [D] and certainly one discriminates, and is able to discriminate, that sweet things are different from white things neither by taste nor by sight nor by both, [E] but by some common part of all sense-organs; [F] for there is a single sense, and the proper sense-organ is single, but the being of the perception of sound is one genus and the being of the perception of color is another). [455a12-22] $]^{50}$

At [A], Aristotle again observes that the senses have powers beyond the paradigmatic ones that make each sense unique, and it is in virtue of those common powers, as he says at [E], that we are able to discriminate (and, later, in virtue of which we are able to sleep and

\footnotetext{
${ }^{49}$ Aristotle also addresses perceptual discrimination later in De Anima III.2, and there it is clear that it too depends on the unity of the perceptual faculty: "Indeed, neither is it possible to discriminate by separate means that sweet is other than white, but both must be evident to some one thing-for otherwise even if I perceived one thing and you another, it would be clear that they were different from each other. But it is evident that one thing says that they are different; for sweet is different from white. Therefore the same thing says [this]; just as it says so it both thinks and perceives - then it is clear that it is not possible to discriminate separate things by separate means" [DA III.2 426b17-23].

${ }^{50}$ There is a tension between this passage and the DA III.2 $425 \mathrm{~b} 12 \mathrm{ff}$ on the issue of whether it is by sight that we perceive that we see: here he says it is not, yet there he implies it is. Some, like Hicks, have seen a very serious conflict here, but I agree with Johansen 2012, p. 196-198 that the difference is merely one of focus - in De Somno Aristotle is focusing on the fact that it is not by sight qua special sense that we perceive that we see; in $D A$ he is trying to provide a reduction, so he wants to show that we don't require anything beyond sight as a general faculty in order to account for perceiving that we see. See also Hamlyn 1968: 202.
} 
wake). ${ }^{51}$ Now if we take it that the accounts of discrimination and joint perception will share significant features ${ }^{52}$, then we shouldn't be surprised to see Aristotle appealing to perceiving that we perceive in this context. And indeed, the fact that he introduces metaperceiving via the instrumental dative (hêi kai hoti horâi kai akouei aisthanetai) is strong support for JPR: it is by perceiving that we perceive that the common potentiality of each of the senses is actualized. Metaperceptions are then able to provide the means by which we discriminateand, I have already argued, jointly perceive - in virtue of the fact that the perceptual faculty has the potential to perceive its own perceptions, and these functions are performed when that potentiality is actualized. When that potentiality lay dormant, on the other hand, we are said to be asleep.

Gregoric agrees that "perceiving that we see and hear" in DSV 2 is not an arbitrarily chosen example of perceptual activity. He notes that Aristotle calls it the "common function" of the common power, and he later says that this type of perceiving must be "something characteristic of waking, and its lack something characteristic of sleep" if the argument is to work (2006: 165, 168). Gregoric concludes that the criterial waking activity is simple awareness that our senses are in activity. ${ }^{53}$ But it is far from obvious that this type of awareness is especially characteristic of waking life, nor is it obvious that a failure to be aware that our senses are active is characteristic of sleeping. ${ }^{54}$ Moreover, Gregoric has no

\footnotetext{
${ }^{51}$ Caston 2002: 779; Gregoric 2006: 165 and Kosman 1975: 517-8 take this passage from DSV to support the view that the common potentiality should be thought of as only arising from the joint operation of the senses and not therefore as being possessed by the senses considered individually. None address the fact that Aristotle here says that each sense (note the singular) has something common, nor that, at 455a22-23, Aristotle says that touch shares most of all in the common potentiality in virtue of the fact that it is separable from the other special senses. Marmodoro 2014 adopts an intermediate position, according to which "each special sense has two types of power: a special one ... and a common one with other senses, in which it participates" but nonetheless "the common power will not be 'common' as a power that is simply replicated in each of the special senses, since this would only endow each of the special senses with an additional set of capabilities each of them can exercise. Rather, what Aristotle attributes to the special senses is a common power that is shared across the special senses, owned jointly by all of them." (260-261)

${ }^{52}$ We have already seen that both require that perception be unified, cf. fn. 49.

${ }^{53}$ Gregoric 2006: 174-189 gives the same account of the explanandum of our master passage [JP].

${ }^{54}$ We spend many waking hours attending to what we are seeing and hearing (Gregoric ascribes perceptual consciousness to the individual senses (Gregoric 2006: 170)), but not nearly as many attending to the fact that our senses of sight and hearing are active.
} 
account of why Aristotle mentions perceptual discrimination at all. Discriminating is certainly not criterial of being awake, for while it is presumably true that one does not discriminate when she is asleep, it is not the case that one is always discriminating while awake.

A preferable reading is the following: earlier in $D S V 2$, Aristotle notes that, in sleep, all of the senses must be dormant simultaneously [455a9-12]. But if simultaneous inactivity is not a massive coincidence, the senses must be united so that they can be turned on and off together. In the quoted passage, then, Aristotle points out that he has in fact already ${ }^{55}$ provided for such a unity, in virtue of the sense faculty's ability to perceive that we see and hear. He illustrates this again, but this time by reference to perceptual discrimination. Here the point seems to be that since it is clear that we can discriminate, and since discrimination requires that we perceive that we see and hear, we do perceive that we see and hear. But if we can perceive that we see and hear, then the senses are unified. Accordingly, their unified inhibition in the context of sleep introduces no further complications. Aristotle concludes the quoted passage by giving his by-now characteristic explanation of the unified faculty: while the perceptual capacity is one in number, the individual senses are diverse in being.

\section{Conclusion}

Theaetetus raises a problem for Aristotle: it claims that we cannot perceive crossmodally, which is a conclusion that Aristotle cannot accept. Given the commonalities that obtain between Aristotle's view on perception and the 'Heraclitean' view on offer in Theaetetus, Aristotle cannot merely assume that joint perception is possible. Instead, he must show how his theory of perception has the tools to account for it.

In this paper, I argued that Aristotle recognized and discharged this obligation in $D S$ 7 and $D A$ III 1-2. First, I showed that he thinks that having a numerically single perception is necessary and sufficient for the apparent unity of that perception. I next argued that the opening of $D A$ III 2-generally thought to be directed towards questions of conscious awareness - is better interpreted as addressing joint perception. Those traditional readings

\footnotetext{
${ }^{55}$ Earlier in the same $D S V$ chapter [455 a8-9]. Aristotle explicitly refers to De Anima.
} 
of the opening of III 2, which I grouped under the heading of 'Awareness Readings', were rejected because they were unable to account for the attendant aporiai, especially the second. The Joint Perception Reading, by contrast, is supported by those aporiai, and especially by their resolution: if the metaperception and the perception are numerically identical, then we have the single, unified state that Aristotle seeks out in $D S 7$ and $D A$ III 1. The metaperceptual account on offer in DA III 2 may also apply to other complex activities, in which case it may be understood as an account of common sensing in general, making Aristotle's account of perception complete and parsimonious, but demonstrating that goes beyond the scope of this paper. $^{56}$

Rosemary Twomey

Queens College CUNY

Bibliography

Burnyeat, M. 1976. "Plato on the Grammar of Perceiving". The Classical Quarterly 26: 29-51. https://doi.org/10.1017/s0009838800033784

Burnyeat, M. 1990. The Theaetetus of Plato. Indianapolis.

Burnyeat, M. 1995a. "Is an Aristotelian Philosophy of Mind Still Credible". In Essays on Aristotle's De Anima. Eds. M. Nussbaum and A. Rorty. Oxford: 15-26. https:// doi.org/10.1093/019823600x.003.0003

Burnyeat, M. 1995b. "How Much Happens When Aristotle Sees Red and Hears Middle C? Remarks on De Anima: 2. 7-8”. In Essays in Aristotle's De Anima. Eds. M. Nussbaum and A. Rorty. Oxford: 421-434.

Burnyeat, M. 2001. “Aquinas on 'Spiritual Change' in Perception”. In Ancient and Medieval Theories of Intentionality. Ed. D. Perler. Leiden: 129-153.

Caston, V. 2002. “Aristotle on Consciousness”. Mind 111: 751-815. https://doi.org/10.1093/ $\operatorname{mind} / 111.444 .751$

${ }^{56}$ I would like to thank Samuel Baker, Wolfgang Mann, Ian McCready-Flora, Jessica Moss, Gary Ostertag, Romina Padró, Nick Pappas, David Rosenthal, Whitney Schwab, Lisa Shapiro, Chris Shields, Monique Whitaker, and especially Iakovos Vasiliou as well as audiences at St. Joseph's University, Humboldt-Universität zu Berlin, and Cambridge University for comments on earlier drafts. 
Caston, V. 2005. "The Spirit and the Letter: Aristotle on Perception". In Metaphysics, Soul, and Ethics in Ancient Thought: Themes from the Work of Richard Sorabji. Ed. R. Salles. Oxford: 245-320.

Caston, V. 2012. "Higher-Order Awareness in Alexander of Aphrodisias". Bulletin of the Institute of Classical Studies 55: 31-49. https://doi.org/10.1111/j.2041-5370.2012.00033.x

Cornford, F. 1957. Plato's Theory of Knowledge. New York. https://doi.org/10.4324/9781315822884

Coope, U. 2005. Time for Aristotle: Physics IV.10-14. Oxford. https://

doi.org/10.1093/0199247900.001.0001

Cooper, J. 1970. "Plato on Sense-Perception and Knowledge (Theaetetus 184-186)". Phronesis 15: 123-146. https://doi.org/10.1163/156852870x00107

Everson, S. 1997. Aristotle on Perception. Oxford. https://doi.org/10.1093/0198238630.001.0001 Fine, K. 1998. "Mixing Matters". Ratio IX: 278-288. https://doi.org/10.1111/1467-9329.00071

Gregoric, P. 2006. Aristotle on the Common Sense. Oxford. https://doi.org/10.1093/

acprof:oso/9780199277377.001.0001

Hamlyn, D. 2002. Aristotle: De Anima. Oxford.

Hamlyn, D. 1968. "Koinê Aisthêsis". The Monist 52: 195-209. https://doi.org/10.5840/monist196852238

Hardie, W. 1964. "Aristotle's Treatment of the Relationship Between the Soul and the Body".

Philosophical Quarterly 14: 53-72. https://doi.org/10.2307/2955441

Hicks, R.D. 1907. Aristotle: De Anima. Cambridge.

Johansen, T.K. 2002. "In Defense of Inner Sense: Aristotle on Perceiving That One Sees".

Proceedings of the Boston Area Colloquium in Ancient Philosophy 21: 235-285. https://

doi.org/10.1163/22134417-90000075

Johansen, T.K. 2007. Aristotle on the Sense Organs. Cambridge. https://doi.org/10.1017/CBO9780511518461

Johansen, T.K. 2012. The Powers of Aristotle's Soul. Oxford. https://doi.org/10.1093/

acprof:oso/9780199658435.001.0001

Kahn, C. 1975. "Sensation and Consciousness in Aristotle's Psychology". In Articles on Aristotle. Eds. J. Barnes, et al. London: 1-31.

Kahn, C. 1981. "Some Philosophical Uses of 'to be' in Plato". Phronesis 26: 105-134. https://

doi.org/10.1163/156852881x00204

Kosman, A. 1975. "Perceiving that We Perceive: On the Soul III,2". The Philosophical Review 84: 499-519. https://doi.org/10.2307/2183851

Kosman, A. 2007. "Commentary on Johansen". Proceedings of the Boston Area Colloquium in Ancient Philosophy 21: 287-297.

Lorenz, H. 2009. “[untitled]”. Review of P. Gregoric's Aristotle on the Common Sense. Rhizai VI: 225-231.

Marmodoro, A. 2014. Aristotle on Perceiving Objects. Oxford.https://doi.org/10.1093/

acprof:oso/9780199326006.001.0001

McCabe, M. M. 2007 "Perceiving that We See and Hear: Aristotle on Plato on Judgment and Reflection". In Perspectives on Perception. Ed. M. M. McCabe and Mark Textor. De Gruyter. p. 143-177. https://

doi.org/10.1515/9783110327557.143

Modrak, D. 1981. "Perception and Judgment in the 'Theaetetus"'. Phronesis 26: 35-54. https://

doi.org/10.1163/156852881x00123

Modrak, D. 1987. Aristotle: The Power of Perception. Chicago.

Osborne, C. 1983. “Aristotle, De Anima 3.2: How Do We Perceive That We See and Hear?”. Classical Quarterly 33: 401-411. https://doi.org/10.1017/s0009838800034662

Polansky, R. 2007. Aristotle’s De Anima. Cambridge. https://doi.org/10.1017/CBO9780511551017 
Ross, W.D. 1955. Aristotle: Parva Naturalia. Oxford.

Ross, W.D. 1961. Aristotle: De Anima. Oxford.

Sorabji, R. 1975. "Body and Soul in Aristotle". In Articles on Aristotle. Eds. J. Barnes, et al. London: $42-64$.

Sorabji, R. 1995. "Intentionality and Physiological Processes: Aristotle's Theory of Sense-Perception". In Essays on Aristotle's De Anima. Ed. M. Nussbaum and A. Rorty. Oxford: 194-227. https://doi.org/10.1093/019823600x.003.0013

Sorabji, R. 2006. Self: Ancient and Modern Insights about Individuality, Life, and Death. Chicago. https://doi.org/10.7208/chicago/9780226768304.001.0001 